\title{
O papel das emoções na relação confiança-exatidão do testemunho
}

\author{
Maria Anabela Bento Marinho Nunes Reis* \\ Maria Purificação Horta \\ Universidade de Lisboa, Faculdade de Medicina, Laboratório de Psicologia Clínica. Lisboa, Portugal
}

Resumo: As emoções interferem com a evocação de acontecimentos importantes, afetando a relação confiançaexatidão (C-E) do testemunho. Foi avaliado o impacto das emoções após a visualização de imagens reais de acidentes de trânsito, bem como a sua influência na evocação posterior, tentando verificar como interferiram com a relação confiança-exatidão. A amostra foi constituída por 150 participantes voluntários com experiência de condução que preencheram questionários de autorrelato do impacto emocional e avaliação de detalhes relativos às imagens apresentadas. Os resultados demonstraram a ausência de relação entre confiança e exatidão no testemunho, tendo os participantes aceito com idêntica confiança conteúdos com informação verdadeira e com informação falsa. As emoções não se correlacionaram com a confiança, embora as emoções de nojo, desprezo e tristeza tenham apresentado uma correlação negativa com a exatidão. Os dados obtidos podem ser úteis no contexto forense.

Palavras-chave: memória, emoção, confiança, precisão, testemunho.

\section{Introdução}

A avaliação da credibilidade do testemunho constituiu nas últimas décadas uma das áreas de maior interesse nas pesquisas sobre a memória do testemunho. Desde cedo estas pesquisas apontaram para o facto de a memória ser muito propensa ao erro em virtude da existência de vários fatores que contribuem para que ocorram as denominadas falsas memórias, sendo a deterioração que se produz na mesma um dos fatores mais conhecidos e estudados (Rodrigues \& Albuquerque, 2007; Santos \& Stein, 2008).

Contudo, pela sua importância em contexto criminal, uma parte significativa da investigação sobre a inexatidão da memória tem vindo a dedicar-se ao estudo do grau de confiança depositado pelos sujeitos no seu testemunho. De uma revisão bibliográfica sobre esta matéria constatamos que os vários estudos, usando como tarefa a identificação de pessoas (Deffenbacher, 1980; Leippe, Wells, \& Ostrom, 1978; Weber \& Brewer, 2006), não tiveram resultados consistentes.

As pesquisas já realizadas podem ser classificadas em dois polos opostos: as que defendem que existe uma relação positiva entre confiança e exatidão (Brigham \& Bothwell, 1983; Nolan \& Markham, 1998; Noon \& Hollin, 1987; Odinot, Wolters, \& Giezen, 2013; Sporer, Penrod, Read, \& Cutler, 1995) e as que referem que pouca ou nenhuma relação existe entre confiança e exatidão (Ames, Kammrath, Suppes, \& Bolger, 2010; Kassin, Ellsworth, \& Smith, 1989; Kassin, Tubb, Hosch, \& Memon, 2001; Odinot, Wolters, \& Koppen, 2009; Perfect, Watson, \& Wagstalf, 1993). Porém, apesar das muitas investigações já realizadas, continuamos a assistir a uma grande divergência de

* Autora correspondente: anabela.marinho@gmail.com opiniões entre os estudiosos do testemunho e os atores do processo judicial.

Existe um número elevado de juízes que acreditam que a confiança que a testemunha expressa no seu relato é um fator decisivo na apreciação que fazem do caso e, por conseguinte, na credibilidade do testemunho (Leippe, Manion, \& Romanazyk, 1992; Lindsay, Wells, \& Reumpel, 1981). Wise e Safer (2004), por exemplo, entrevistaram juízes sobre este assunto e verificaram que $34 \%$ dos entrevistados admitiram que, durante o julgamento, a confiança de uma testemunha é um bom prenúncio da exatidão das suas declarações. Levett e Kovera (2009) também referiram que é frequente no meio forense acreditar-se que uma memória detalhada e segura dos factos é mais credível.

Apesar dos muitos estudos já realizados podemos constatar que a investigação sobre a relação C-E continua a suscitar interesse, nomeadamente no que se refere ao papel das emoções nessa relação. Mas também a literatura revisitada sobre o efeito de alerta na memória apresenta resultados mistos (Christianson, 1992; Deffenbacher, 1983; Kensinger, 2004; Lindsay, 1994; Loftus, 1979, 2005; McNeely, Dywan, \& Segalowitz, 2004; Reisberg \& Heuer, 2004) pois, dependendo da intensidade da sua ativação e da forma como os sujeitos a vivenciam, as emoções podem ter efeitos positivos ou negativos na memória.

As abordagens iniciais (Lei de Yerkes-Dodson, 1908) consideraram que existe uma função em forma de $U$ invertido entre desempenho e excitação, e, como tal, baixos e altos níveis de excitação foram associados a efeitos prejudiciais na memória. Christianson (1992) veio rejeitar esta abordagem, tendo concluído que a memória para os detalhes centrais é reforçada pelo aumento da emotividade, enquanto a memória para os detalhes periféricos é prejudicada. Outras pesquisas (Yuille \& Cutshall, 1986) 
têm demostrado como o stresse, por exemplo, atua sobre a memória das testemunhas oculares, tendo sido verificado, num estudo com testemunhas oculares de uma situação de crime real, que as pessoas que sofreram mais stresse foram as que lembraram mais detalhes, não obstante o estudo não referir a qualidade dessa evocação.

Embora sabendo que a ativação emocional é uma característica dos acontecimentos reais, os estudos já realizados nas últimas três décadas pouco conhecimento nos revelam sobre os efeitos da emoção na relação C-E, sobretudo aquando da visualização de imagens reais com carga emocional. Com efeito, alguns estudos sugerem que emoções como a tristeza ou o stresse provocam um maior número de erros (Deffenbacher, Bornstein, Penrod, \& McGorty, 2004) e que a precisão da memória diminui com o aumento da excitação. Contudo, Christianson (1992) obteve conclusões diferentes, argumentando que não havia evidências para apoiar a noção de que o stresse emocional debilita a memória da testemunha ocular. Além disso, argumentou que a Lei de Yerkes-Dodson não é uma descrição adequada para a relação entre o stresse emocional e a fidelidade da memória da testemunha ocular. Este autor sugeriu que a memória para eventos emocionais negativos é melhor do que para eventos neutros e que uma melhor memória para os detalhes centrais se deve ao facto de que os acontecimentos com carga emocional negativa causam uma maior focalização da atenção e, por conseguinte, um aumento dos detalhes dentro desse foco de atenção.

Estudos mais recentes (Sharot, Martorella, Delgado, \& Phelps, 2007; Talarico \& Rubin, 2003) sugerem que a emoção aumenta a sensação subjetiva da lembrança, isto é, o facto de se vivenciar um evento com carga emocional faz criar uma sensação de confiança na exatidão da memória. De igual modo, alguns estudos sobre as denominadas memórias cintilantes (flashbulb memories) sugerem que a maioria das pessoas possui elevados níveis de confiança para este tipo de memórias detalhadas de factos com carga emocional, embora os detalhes das suas memórias sejam incorretos (Loftus \& Bernstein, 2005; Talarico \& Rubin, 2003). Estes autores estudaram a memória que estudantes universitários tinham sobre o 11 de Setembro de 2001 e concluíram que não existia grande diferença entre a memória dos detalhes deste acontecimento e dos de outro evento qualquer, apesar do stresse causado por aquele acontecimento.

Também nos estudos sobre a modelação da memória para a informação contextual provocada pela emoção (Mather, 2007) apresentaram resultados inconsistentes. Referem que a emoção não faz aumentar a memória para os detalhes contextuais, o que parece ser inconsistente com uma grande parte da literatura que indica que a emoção aumenta a exatidão da memória. Vários pesquisadores defenderam que as memórias para acontecimentos emocionais da vida das pessoas (casamento, nascimento ou morte de um parente, uma doença, etc.) estavam imunes à contaminação (Brown \& Kulik, 1977). Contudo, passados 40 anos, os estudiosos da memória do testemunho estão convictos que este tipo de memórias emocionais não são impermeáveis à distorção e ao esquecimento quando se apela ao detalhe, sendo que estudos mais recentes (Mather, 2007; Reisberg, \& Heuer, 2004) têm sugerido que as pessoas estão mais predispostas a lembrar detalhes visuais dos itens negativos comparados com os neutros. Isto quer dizer que as emoções negativas aumentam mais a exatidão da memória do que as emoções positivas, à semelhança dos achados de Rimmele et al. (2011). Estes pesquisadores apresentaram fortes evidências de que estímulos negativos estão associados a lembranças mais confiantes que estímulos neutros, mas com uma menor acurácia na lembrança do detalhe contextual.

Podemos, pois, concluir que não há consenso sobre a melhor forma de caracterizar os tipos de informação incrementada pelas emoções, continuando a existir discussão sobre o facto de as emoções melhorarem os detalhes a serem lembrados em detrimento das memórias não emocionais (Denburg, Buchanan, Tranel, \& Adolphs, 2003; Kensinger, Garoff-Eaton, \& Schacter, 2007; Soleti, Curci, Bianco, \& Lanciano, 2012). Estudos com neuro-imagem indicaram que os itens emocionais podem ser associados a uma baixa atividade visual (Dolcos, LaBar, \& Cabeza, 2005; Fenker, Schott, Richardson-Klavehn, Heinze, \& Duzel, 2005; Sharot, Delgado, \& Phelps, 2004), havendo evidência de que as memórias emocionais não contêm o mesmo detalhe percetual das não emocionais (Sharot et al., 2004). Também Kensinger e Schacter (2006) concluíram que a emoção não tem qualquer efeito na habilidade dos sujeitos para lembrarem, mas, por outro lado, Soleti et al. (2012) mostraram que quando as testemunhas vivenciam acontecimentos com carga emocional, esta carga emocional pode, mais tarde, comprometer a exatidão do seu testemunho.

A literatura aqui revisitada mostra-nos que os estudiosos do testemunho ainda têm uma visão pessimista da relação entre confiança e exatidão do testemunho mas que, por outro lado, os operadores do sistema judiciário continuam a acreditar que a confiança é um bom indicador da exatidão, ou seja, da qualidade do testemunho.

Tomando como ponto de partida esta dicotomia de posições, pretendemos refletir sobre os seguintes pressupostos: que tipo de relação existe entre confiança e exatidão durante um testemunho; qual o grau de confiança que os sujeitos depositam na informação verdadeira e na informação falsa introduzida pós-evento e quais as emoções que constituem um facilitador na recuperação correta da informação e na confiança do sujeito.

\section{Método}

\section{Participantes}

A amostra foi constituída por 150 adultos voluntários (sendo 79 homens e 71 mulheres), com média de idades de 43 anos $(M=43,26 ; S D=8,857), 55 \%$ com habilitações académicas iguais ou superiores ao grau de licenciatura e 
com experiência e regularidade de condução de 20 anos $(\mathrm{M}=20,40 ; \mathrm{SD}=8,364)$, pois pretendíamos familiaridade com os conteúdos a visionar. Todos os indivíduos que participaram neste estudo foram avaliados respeitando os procedimentos destinados a garantir a boa compreensão da natureza da investigação, bem como o conteúdo dos instrumentos. Todos assinaram um termo de aceitação das condições da experiência e foi-lhes explicado a natureza confidencial do estudo e o tempo que iriam dispender ao disponibilizarem-se para colaborar.

\section{Instrumentos}

Estímulos: partindo do pressuposto que os filmes provocam emoções (Gerrards-Hesse, Spies, \& Hesse, 1994; Hesse, Spies, Hanze, \& Gerrards, 1992; Hettema, 1994) e, embora muitos estudos utilizem filmes do circuito comercial (Schaefer, Nils, Sanchez, \& Philippot, 2010) optamos por construir o nosso próprio filme, de modo a evitar efeitos de habituação e o conhecimento prévio das cenas. Construímos assim um pequeno filme, com imagens reais de acidentes de trânsito, considerando que é algo que se aproxima da realidade com que os participantes se confrontam e que, dado o grande número de ocorrências, os pode implicar como testemunhas. As imagens constantes do filme foram selecionadas de gravações cedidas pelas Brigadas de Trânsito das forças policiais e obtidas, na zona de Lisboa, no período de uma semana e com a duração de 8 minutos. Numa primeira fase selecionamos 5 minutos de imagens que após serem avaliadas por 20 condutores voluntários permitiram que fossem eliminadas as imagens que não eram discriminativas. $\mathrm{O}$ resultado final traduziuse num filme de 3 minutos com acidentes rodoviários e manobras perigosas.

Questionário: para a fase de recuperação da informação foi construído um questionário composto por duas partes: a primeira parte destinou-se à caracterização individual dos participantes, incluindo uma breve caracterização da sua atividade como condutores e da sua participação em acidentes e a segunda parte contemplou um teste de memória. Este teste, à semelhança do nosso filme, também foi construído de base e envolveu a realização de um pré-teste de acordo com os critérios determinados para aferir da sua validade e confiabilidade como instrumento de avaliação. Assim, uma vez que não existem regras específicas para determinar o número adequado de avaliadores para participarem na validação do conteúdo (Anastasi, 1986; Cronbach, 1971), optamos por usar 20 avaliadores voluntários. Cada questionário foi acompanhado de um termo de interesse, explicando os objetivos do estudo e solicitando a colaboração para a avaliação das questões em relação à sua redação, compreensão e adequação ao contexto quotidiano do trânsito, bem como à veracidade do seu conteúdo em relação às imagens visionadas. $\mathrm{O}$ questionário foi, primeiramente, construído com seis questões, sendo três com informação falsa e três com informação verdadeira. Os avaliadores foram orientados a pontuar cada questão conforme a sua opinião, da seguinte maneira: 1 - Concordo totalmente, 2 - Concordo parcialmente e 3 - Discordo. Adicionalmente, também era solicitado que assinalassem se consideravam a questão verdadeira ou falsa. Havia espaço para comentários, no qual poderiam dar sugestões ou fazer críticas. Utilizamos o índice de, no mínimo, 80\% de concordância total ou parcial entre os avaliadores, para determinar da validade do conteúdo de cada questão (Cronbach, 1971). Os resultados da análise da qualidade das questões constituiram a base para confirmarem a validade e a adequação do instrumento às necessidades dos participantes.

Deste modo eliminamos duas questões e construímos o nosso teste de memória com as quatro questões que melhor se encaixavam nos interesses da nossa investigação (duas com informação verdadeira (Q2 - Um carro despistou-se para o lado esquerdo da via indo embater contra um sinal de informação de trânsito; Q4 - O carro que se despistou numa curva por excesso de velocidade era de cor vermelha) e duas com informação falsa $(\mathrm{Q} 1$ - O homem que conduzia a viatura ligeira pelas ruas da cidade e que se chocou contra um furgão branco estacionado usava boné; Q3 - O homem da viatura que se despistou quando um cão atravessou a via, saiu da viatura pelo próprio pé). Fizemos corresponder, a cada uma das questões, 2 colunas onde era solicitado que assinalassem V (verdadeiro) ou $\mathrm{F}$ (falso) e onde também era estabelecida a correspondência com uma escala (tipo Lickert) de três graus, para verificação do grau de confiança atribuído em cada escolha. Esta escala variou entre 1 (pouca confiança), 2 (alguma confiança) e 3 (muita confiança).

Escala de avaliação de emoções: para medir o impacto emocional do filme foi utilizada a parte referente às emoções da Escala de Emoções, Sensações e Cognições 96 (EESC96), instrumento construído no âmbito da investigação para obtenção do grau de doutor de Queirós (1997a) e adaptado por vários autores (Queirós, 1997b; Queirós, van Asselen \& Oliveira, 2000; Torres \& Guerra, 2003, e Torres et al. 2011). Esta escala corresponde a uma versão modificada da Differential Emotion Scale desenvolvida por Izard que avalia as emoções primárias numa escala de intensidade que varia entre zero e cinco. As 11 emoções primárias contempladas na escala (Izard, 1991; Izard \& Buechler, 1980; Queirós, 1997a) são o interesse, alegria, surpresa, cólera, nojo, desprezo, medo, angústia, vergonha, culpa e tristeza. Estas emoções são classificadas como positivas ou negativas, de acordo com a menor ou maior probabilidade, respectivamente, de acarretarem consequências indesejáveis para o sujeito. Como positivas são consideradas o interesse, a alegria e a surpresa e como negativas são consideradas as restantes oito emoções. Para avaliar as emoções específicas, os participantes foram solicitados a avaliar a intensidade dos seus estados emocionais durante a visualização de cada filme. O formato de resposta para cada item era de seis pontos, variando entre 0 (Não sinto a emoção) e 5 (Sinto a emoção com muito intensidade). Era pedido aos participantes que assinalassem com uma cruz na coluna respetiva a intensidade com que eles sentiram cada uma 
das emoções. Para ser mais facilmente identificada, cada emoção era formada por dois termos sinónimos.

Procedimentos: o filme foi exibido a grupos de dois participantes de cada vez, sempre nas mesmas condições. Aos participantes, depois de confortavelmente instalados, foram dadas as instruções necessárias e esclarecidas as dúvidas, sendo pedido que olhassem com atenção para o filme a exibir pois seria solicitado mais tarde que recuperassem informação das imagens visionadas. Após o visionamento do filme foi pedido que preenchessem a escala de emoções e a parte do questionário composto pelos dados sociodemográficos e de condução que, em simultâneo, serviam como manobra de distração (Higham, 1998; Paterson, Kemp \& Forgas, 2009; Paz-Alonso \& Goodman, 2008) para a prova de memória. Por fim era solicitado que preenchessem o teste de memória. A ordem de apresentação das quatro questões foi controlada (2 questões falsas e 2 questões verdadeiras, 2 questões verdadeiras e 2 questões falsas, questões verdadeiras e questões falsas intercaladas) de modo a garantir a validade do estudo.

\section{Resultados}

Da análise estatística dos dados e efetuado o teste de correlação de Pearson verificamos que não existe qualquer tipo de correlação entre a confiança demonstrada pelos participantes e a exatidão das suas respostas $(R=-0,087$; $\mathrm{p}=0,291)$.

A análise das respostas às quatro questões formuladas (duas com informação verdadeira e duas com informação falsa) e rescpetivo grau de confiança atribuído, demonstrou que existem diferenças significativas para 0 comportamento manifestado pelos participantes para as questões verdadeiras e falsas (Figura 1), pois $41 \%$ das respostas dadas eram incorretas e destas $71 \%$ diziam respeito às questões formuladas com informação falsa. Uma grande percentagem de participantes assumiu como verdadeira a informação falsa e atribuiu-lhes significativa confiança
(Q1. $\chi^{2}=17,713 ; p=0,000$ : Q3. $\chi^{2}=4,882 ; p=0,087$ ). Para as questões com informação verdadeira encontramos um comportamento oposto, tendo os participantes manifestado maior confiança para as respostas corretas (Q2. $\chi^{2}=2,511$; $\mathrm{p}=0,285$ : $\mathrm{Q} 4 \chi^{2}=31,248 ; \mathrm{p}=0,000$ ). Concluímos que quando a informação é verdadeira os participantes atribuem mais confiança às respostas corretas mas quando a informação é falsa atribuem maior confiança às respostas incorretas.

No que se refere à intensidade emocional (Tabela 1), verificamos que a emoção mais intensamente experimentada foi o interesse, logo seguida da surpresa e da tristeza. Mas, de uma maneira geral, todas as emoções foram moderadamente ativadas com exceção da alegria, o que se compreende devido ao tipo de conteúdo visionado, mas também da culpa que, de acordo com Queiróz (1997a), se define como uma emoção associada à responsabilidade pessoal pela violação de regras internas. Relativo à influência das emoções na relação C-E, verificamos que não existe qualquer correlação das emoções com a confiança, mas existem correlações significativas das emoções cólera, nojo e tristeza, com a exatidão e que estas correlações são todas negativas.

\section{Discussão}

Pelo que podemos concluir, este estudo revelou a inexistência de correlação entre confiança e exatidão, ou seja, que o fator confiança não é um indicador confiável de precisão do testemunho. Os nossos resultados encontram fundamentação em várias investigações (Ames et al., 2010; Kassin et al., 1989; Odinot et al., 2009; Sporer et al., 1995), embora Wells e Murray (1984) referenciem que $42 \%$ dos trabalhos analisados, nesta área de estudo do testemunho, sustentaram que existe uma correlação positiva e significativa entre a confiança da testemunha e a exatidão do seu testemunho.

No que se refere ao nível de confiança associado às questões verdadeiras (Q2 e Q4), só é ligeiramente superior

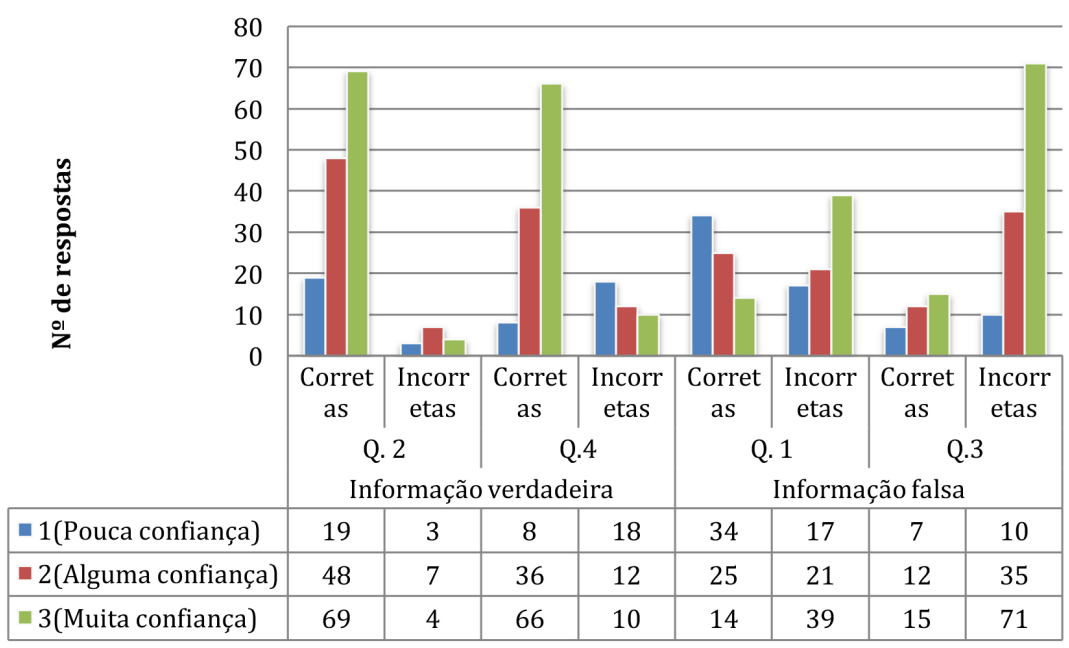

Figura 1. Distribuição do número de sujeitos por grau de confiança manifestado para as questões verdadeiras (Q.2 e Q.4) e para as questões falsas (Q.1 e Q.3) 
Tabela 1

Médias da intensidade das emoções e correlação das emoções com o grau de confiança e de exatidão

\begin{tabular}{lcccc}
\hline Emoções & Média & Desvio padrão & Confiança & Exatidão \\
\hline Interesse ou curiosidade & 3,23 & 1,201 & 0,066 & $-0,010$ \\
Alegria ou felicidade & 0,65 & 1,087 & 0,002 & $-0,044$ \\
Surpresa ou espanto & 3,06 & 1,352 & $-0,106$ & $-0,001$ \\
Angústia ou ansiedade & 2,72 & 1,405 & $-0,044$ & $-0,062$ \\
Cólera ou irritação & 2,77 & 1,590 & $-0,017$ & $-0,089$ \\
Nojo ou repugnância & 2,22 & 1,774 & 0,013 & $-0,313^{* *}$ \\
Desprezo ou desdém & 1,93 & 1,585 & $-0,071$ & $-0,184^{*}$ \\
Medo ou receio & 2,88 & 1,658 & $-0,086$ & $-0,111$ \\
Vergonha ou humilhação & 1,98 & 1,734 & $-0,007$ & $-0,144$ \\
Tristeza ou desânimo & 2,97 & 1,622 & $-0,024$ & $-0,161^{*}$ \\
Culpa ou remorso & 0,95 & 1,397 & $-0,067$ & 0,027 \\
\hline
\end{tabular}

$* * \mathrm{p}<0,01 * \mathrm{p}<0,05$

ao nível de confiança associado às questões falsas (Q1 e Q3), tendo os participantes alguma dificuldade em distinguir as respostas corretas e incorretas. Contudo, é de salientar que, embora a Questão 1 (falsa) apresente níveis de respostas incorretas abaixo dos níveis de respostas corretas das Q2 e Q4 (ambas verdadeiras), as respostas incorretas para a Q3 (falsa) atingiram níveis semelhantes e até ligeiramente superiores ao das respostas corretas para as Q2 e Q4. A explicação poderá estar no facto de que os sujeitos utilizaram diversas categorias de resposta para determinar a confiança que devem atribuir às suas respostas (Higham, Luna, \& Bloomfield, 2011). Uma dessas chaves poderia ter sido a exatidão real da resposta, o que se traduziria numa melhor relação C-E, mas que não se veio a verificar. Outra explicação poderá ser o facto de a resposta ser apenas de aceitação ou rejeição, situação que pouco pode contribuir para o estabelecimento de uma adequada relação C-E. Estes resultados contrariam a maioria dos estudos que defendem que existe uma maior confiança para as respostas corretas (Garcia-Bajos \& Migueles, 2003; Loftus, Miller \& Burnes, 1978; Loftus, Donders, Hoffman, \& Schooler, 1989), pois os resultados aqui obtidos mostram uma elevada confiança atribuída às respostas corretas quando a informação é verdadeira, mas também uma significativa confiança nas respostas incorretas quando a informação é falsa. Este comportamento pode encontrar justificação teórica nas conclusões obtidas por Deffenbacher et al. (2004) que defendem que, ao introduzir-se informação pós evento, esta é assimilada e assumida pelos sujeitos como informação verdadeira. Assim os participantes deste estudo, ao adquirirem consciência de que a sua resposta é correta codificaram esse facto como tal, o que veio, mais tarde, determinar a qualidade da resposta. De acordo com as hipóteses defendidas por estes pesquisadores, a correlação C-E está modulada pela qualidade das condições de codificação de uma testemunha quando observa um acontecimento. Significa dizer que os sujeitos acreditam que as suas declarações são exatas, não distinguindo a informação falsa.
Por outro lado, e à semelhança de considerações efetuadas em estudos recentes (Stefanie \& Martine, 2012), poderão as questões fechadas não ter encorajado os participantes a pensarem muito sobre as respostas, uma vez que podiam responder apenas "sim" e "não". Por outro lado, poderá também ter havido uma banalização dos conteúdos observados, pela familiaridade com os mesmos, no dia-a-dia dos participantes. Estes resultados podem ser explicados à luz dos estudos de Talarico e Rubin (2003) que referem que o estar familiarizado com os estímulos observados provoca uma sensação de excesso de confiança na exatidão das suas memórias, levando a prestar pouca atenção nas escolhas realizadas.

Em resposta aos dois primeiros pressupostos deste estudo, a principal conclusão que podemos retirar é que a confiança não parece ser um forte indicador da exatidão da resposta, tendo como base de trabalho um teste de recordação com pistas verdadeiras e falsas. A grande diferença nos índices de confiança para as respostas corretas da informação verdadeira e para as respostas incorretas da informação falsa permite traçar um cenário pouco otimista sobre as possibilidades da relação entre confiança e exatidão ser positiva. De facto, os sujeitos não têm dúvidas ao atribuir muita confiança às respostas corretas o que permitiria apontar para uma relação positiva entre C-E, mas tal situação só ocorre quando a informação é verdadeira. A confiança demonstrada para as questões falsas, em especial a muita confiança atribuída à Q3, mostra as limitações da confiança como um preditor de exatidão. Estes resultados também levam a refletir sobre se a forma de perguntar poderia ter tido alguma influência no excesso de confiança atribuído a esta questão. Luna e Martin-Luengo (2012) sugerem que a forma de perguntar pode ter influência na discrepância dos resultados que se possam obter. Contudo, não podemos deixar de realçar que, em contexto forense, as testemunhas são incentivadas a responder a questões formuladas por vários e diferentes operadores do sistema judiciário. 
De modo a poder responder ao terceiro pressuposto, fomos analisar o efeito das emoções na consistência do testemunho e na sua relação com a confiança, procurando identificar as emoções que pudessem provocar qualquer tipo de efeito nesta relação C-E. Verificamos que, de um modo geral, todas as emoções foram pouco ou moderadamente ativadas, o que encontra justificação na banalização dos conteúdos observados, conforme explicação referida anteriormente.

Os resultados revelaram que não existe qualquer correlação entre as emoções e a confiança que os participantes tiveram no seu testemunho. Podemos, assim, inferir que as emoções não contribuem para reforçar nem para diminuir o grau de confiança dos sujeitos nas suas escolhas. Apesar de não haver qualquer correlação entre as emoções e a confiança, o mesmo não se passou em relação à exatidão. Algumas emoções foram correlacionadas com a exatidão, afetando-a negativamente. A uma maior intensidade emocional das emoções nojo, desprezo e tristeza correspondeu uma menor exatidão. Estes resultados poderão ser explicados pela seletividade da memória e são coerentes com outros estudos (Ellis, 1996; Kesinger \& Schacter, 2006; Loftus et al., 1978) que sugerem que as memórias emocionais negativas levam os sujeitos a terem menor capacidade de análise e pior evocação. Possivelmente, a forma de codificação da informação e a intensidade da vivência das três emoções responsáveis pela correlação negativa verificada, foi suficiente para provocar stresse que, por sua vez, diminuiu a probabilidade de uma correspondência positiva com a exatidão. Por outro lado também o facto de as imagens serem parte do quotidiano dos sujeitos podem ter criado um excesso de confiança na exatidão da memória à semelhança dos achados de Sharot et al. (2007) e Talarico e Rubin (2003), que defendem que a emoção aumenta a sensação subjetiva de lembrar, isto é, o facto de vivenciar um evento com carga emocional faz criar uma sensação de confiança na exatidão da memória. Deffenbacher et al. (2004) também referem a tristeza e o stresse como afetando negativamente a memória e notese que duas das emoções observadas e correlacionadas negativamente com a exatidão (nojo e desprezo) estão enquadradas na tríade da hostilidade (Queirós, 1997a) e são responsáveis por comportamentos de rejeição de conteúdos avaliados como desagradáveis. Assim, do ponto de vista social, os sujeitos, ao rejeitarem o conteúdo das imagens, poderão ter feito associação com o seu próprio conhecimento dessa realidade e tal facto provocou o stresse suficiente para pôr em risco a capacidade de manter o foco da atenção nas imagens, distraindo-os da sua tarefa principal e afetando negativamente a capacidade do seu testemunho. Izard (1991) considera que cada emoção primária tem uma tendência motivacional única, uma organização neuronal particular, configurações expressivas distintas e propriedades experienciais específicas, e na sua teoria diferencial das emoções defende que a consciência é organizada pelas emoções primárias que direcionam os processos sensoriais, percetivos e cognitivos (Izard \& Buechler, 1980).

Os resultados encontrados contêm importantes implicações práticas para o contexto forense. Permitem concluir que informações falsas introduzidas pelas perguntas podem ser incorretamente consideradas como verdadeiras com elevado grau de confiança, sendo coerentes com estudos até agora realizados, mas é suposto esperar que as testemunhas de um crime sejam sujeitas a diferentes interrogatórios e, portanto, diferentes formas de perguntar. Estes resultados sugerem que as emoções negativas de nojo, desprezo e tristeza, mesmo que vivenciadas com moderada intensidade, podem comprometer a exatidão o que mostra a vulnerabilidade da memória da testemunha. Contudo, estes resultados podem ter sido influenciados pelas limitações que podemos apontar ao nosso estudo, nomeadamente o facto de ser de tipo exploratório com uma amostra de voluntários, não tendo até ao momento encontrado nenhum outro estudo que tivesse analisado como determinadas emoções interferem na relação confiança e exatidão. Além disso, seria importante compreender melhor o que têm de diferente as duas questões com informação falsa (Q1 e Q3) para terem provocado nos participantes um comportamento tão diferente na atribuição dos níveis de confiança, bem como perceber porque foram as emoções nojo, desprezo e tristeza as responsáveis pela inexatidão da memória e não outras. Devido à pertinência da aplicação no contexto forense seria interessante em futuras investigações considerar, com recurso a instrumentos e situações diferentes, como se organizam as várias emoções, como são reguladas em diferente contextos (Gutiérrez \& Muñoz-Martínez, 2013) e como interferem na relação confiança e exatidão.

\section{The role of emotions in the trust-accuracy relationship during the testimony}

Abstract: Emotions interfere with the recall of major events, affecting the trust-accuracy relationship during the testimony. The
impact of emotions after the participants see images of real traffic accident was assessed, as well its influence on posterior recall,
trying to verify how they interfere with the trust-accuracy relationship. The sample consisted of 150 participants with driving
experience who voluntary fulfilled questionnaires on their emotional impact and details related with the images shown. The
results demonstrated the absence of relationship between trust and accuracy in testimony, as the participants accepted with
identical belief both true and false information. Emotions do not relate with trust, although emotions such as disgust, contempt
and sadness presented a negative correlation with accuracy. The data obtained can be useful in the forensic context.

Keywords: memory, emotion, trust, accuracy, testimony. 


\section{Le role des emotions dans la rélation confiance-exactitude du témoignage}

Résumé: Les émotions interfèrent dans l'évocation des événements importants et affectent la confiance-précision dans le témoignage. On a évalué l'impact des émotions après la visualisation des images réelles d'accidents de trafic, ainsi que leur influence sur l'évocation ultérieure, en essayant de voir son interférance dans la relation confiance- exactitude. L'échantillon était composé de 150 participants avec expérience de conduite, qui volontairement ont rempli des questionnaires sur l'impact émotionnel et l'évaluation des détails concernant les images présentées. Les résultats ont montré l'absence de relation entre la confiance et l'exactitude dans le témoignage, et les participants ont accepté avec la même confiance les contenues ayant des vraies et des fausses informations. Les émotions n'étaient pas corrélées avec la confiance, bien que les émotions de dégoût, de mépris et de tristesse ont montré une corrélation négative avec l'exactitude. Les données obtenues peuvent être utiles dans le contexte forensique.

Mots-clés: mémoire, émotion, confiance, exactitude, témoignage.

\section{El papel de las emociones en la relación confianza-exactitud del testimonio}

Resumen: Las emociones interfieren en la evocación de acontecimientos importantes, afectando la relación confianza-exactitud (C-E) del testimonio. En este artículo se evaluó el impacto de las emociones después de la visualización de imágenes reales de accidentes de tránsito, así como su influencia en la evocación posterior, intentando comprobar cómo interfirieron en la relación confianza-exactitud. La muestra se constituyó por 150 participantes voluntarios con experiencia de conducción, que respondieran a cuestionarios de auto-relato sobre el impacto emocional y la evaluación de los detalles de las imágenes presentadas. Los resultados demostraron la ausencia de relación entre confianza y exactitud en el testimonio, siendo que los participantes aceptaron con igual confianza los contenidos con informaciones verdaderas y falsas. Las emociones no se correlacionan con la confianza, aunque las emociones de asco, desprecio y tristeza hayan manifestado una correlación negativa con la exactitud. Los datos obtenidos pueden tener utilidad para el contexto forense.

Palabras clave: memoria, emoción, confianza, precisión, testimonio.

\section{Referências}

Ames, D. R., Kammrath, L. K., Suppes, A., \& Bolger, N. (2010). Not so fast: The (not-quite-complete) dissociation between accuracy and confidence in thin-slice impressions. Personality and Social Psychology Bulletin, 36(2), 264-277. doi: 10.1177/0146167209354519

Anastasi, A. (1986). Evolving concepts of test validation. Annual Review of Psychology, 37, 1-15.

Brigham, J. C., \& Bothwell, R. K. (1983). The ability of prospective jurors to estimate the accuracy of eyewitness identifications. Law and Human Behavior, 7, 19-30. doi: https://www.ncjrs.gov/App/Publications/ abstract.aspx? ID =88099

Brown, R., \& Kulik, J. (1977). Flashbulb memories. Cognition, 5, 73-99. 337-349. doi: 10.1016/00100277(77)90018-X

Cronbach, L. J. (1971). Test validation. In R. L. Thorndike (Ed.), Educational measurement (pp. 443-507). Washington, DC: American Council on Education.

Christianson, S. Å. (1992). Emotional stress and eyewitness memory: A critical review. Psychological Bulletin, 112, 284-309.

Deffenbacher, K. A. (1980). Eyewitness accuracy and confidence: Can we infer anything about the relationship? Law and Human Behavior, 4, 243-260. doi: https://www. ncjrs.gov/App/Publications/abstract.aspx?ID=77855
Deffenbacher, K. A. (1983). The influence of arousal on reliability of testimony. In S. M. A. Lloyd-Bostock, \& B. R. Clifford (Eds.), Evaluating witness evidence (pp. 235-251). Chichester, England: Wiley.

Deffenbacher, K. A., Bornstein, B. H., Penrod, S. D., \& McGorty, E. K. (2004). A meta-analytic review of the effects of high stress on eyewitness memory. Law and Human Behavior, 28(6), 687-706. doi: http:// digitalcommons.unl.edu/psychfacpub/182

Denburg, N. L., Buchanan, T. W., Tranel, D., \& Adolphs, R. (2003). Evidence for preserved emotional memory in normal older persons. Emotion, 3(3), 239-253. doi: 10.1037/1528-3542.3.3.239

Dolcos, F., LaBar, K. S., \& Cabeza, R. (2005). Remembering one year later: Role of the amygdala and the medial temporal lobe memory system in retrieving emotional memories. Proceedings of National Academy of Sciences of EUA, 102(7), 2626-2631. doi: 10.1073_pnas.0409848102

Ellis, J. (1996). Prospective memory of the realization of delayed intentions: A conceptual framework for research. In M. Brandimonte, G. O. Einstein, \& M. A. McDaniel (Eds.), Prospective memory: Theory and application (pp. 1-22). Mahwah, NJ: Erlbaum.

Fenker, D. B., Schott, B. H., Richardson-Klavehn, A., Heinze, H. J., \& Duzel, E. (2005). Recapitulating 
emotional context: activity of amygdala, hippocampus and fusiform cortex during recollection and familiarity. European Journal of Neurosciences, 21, 1993-1999. doi: PMID 15869492

García-Bajos, E., \& Migueles, M. (2003). False memories for script actions in a mugging account. European Journal of Cognitive Psychology, 15, 195-208. doi: 10.1080/09541440244000102.

Gerrards-Hesse A., Spies K., \& Hesse F. W. (1994). Experimental inductions of emotional states and their effectiveness: a review. British Journal of Psychology, $85,55-78$.

Hesse, F., Spies, K., Hanze, M., \& Gerrards, A. (1992). Experimental induction of moods states: alternatives to the Velten method. Zeitschrift fur Experimentelle und Angewandte Psychologie, 39, 559-580.

Hettema, J. (1994). Psychophysiological assessment of personality using films as stimuli. Personality and Individual Differences, 16, 167-178.

Higham, P. A. (1998). Believing details known to have been suggested. British Journal of Psychology, 89, 265-283.

Higham, P. A., Luna, K., \& Bloomfield, J. (2011). Tracestrength and source monitoring accounts of accuracy and metacognitive resolution in the misinformation paradigm. Applied Cognitive Psychology, 25, 324-335. doi: 10.1002/acp.1694

Izard, C. (1991). The psychology of emotions. New York: Plenum Press.

Izard, C. \& Buechler, S. (1980). Aspects of consciousness and personality in terms of differential emotions theory. In R. Plutchik, \& H. Kellerman (Eds.), Emotion: theory, research and experience (Vol. 1, pp. 105-187). New York: Academic Press.

Kassin, S. M., Ellsworth, P. C., \& Smith, V. L. (1989). The 'general acceptance' of psychological research on eyewitness testimony: A survey of experts. American Psychologist, 44, 1089-1098.

Kassin, S. M., Tubb, V. A., Hosch, H. M., \& Memon, A. (2001). On the 'general acceptance' of eyewitness testimony research: A new survey of the experts. American Psychologist, 5, 405-416. doi: 10.1037//0003066X.56.5.405

Kensinger, E. A. (2004). Remembering emotional experiences: The contribution of valence and arousal. Reviews in the Neurosciences, 15, 241-251. doi: 10.1515/ REVNEURO.2004.15.4.241

Kensinger, E. A., Garoff-Eaton, R. J., \& Schacter, D. L. (2007). Effects of emotion on memory specificity: Memory trade-offs elicited by negative visually arousing stimuli. Journal of Memory and Language, 56, 575-591. doi: 10.1016/j.jml.2006.05.004

Kensinger, E. A., \& Schacter, D. L. (2006). Reality monitoring and memory distortion: Effects of negative, arousing content. Memory and Cognition, 34, 251-260.

Leippe, M. R., Manion, A. P., \& Romanczyk, A. (1992). Eyewitness persuasion: How and how well do fact finders judge the accuracy of adults' and children's memory reports? Journal of Personality and Social Psychology, 63, 181-197. doi: 10.1037/0022-3514.63.2.181

Leippe, M. R., Wells, G. L., \& Ostrom, T. M. (1978). Crime seriousness as a determinant of accuracy in eyewitness identification. Journal of Applied Psychology, 63(3), 345-351. doi: 10.1037/0021-9010.63.3.345

Levett, L. M., \& Kovera, M. B. (2009). Psychological mediators of the effects of opposing expert testimony on juror decisions. Psychology, Public Policy, and Law, 15(2), 124-148. doi: 10.1037/a0016309

Lindsay, D. S. (1994). Memory source monitoring and eyewitness testimony. In D.F. Ross, J. D. Read, \& M. P. T. (Eds.), Adult eyewitness testimony: Current trends and developments (pp. 27-55). New York: SpringerVerlag.

Lindsay, R., Wells, G. L., \& Rumpel, C. M. (1981). Can people detect eyewitness identification accuracy within and across situations? Journal of Applied Psychology, 66, 79-89. doi: 10.1037/0021-9010.66.1.79

Loftus, E. F. (1979). Eyewitness testimony. Boston: Harvard University Press.

Loftus, E. F. (2005). Planting misinformation in the human mind: A 30-year investigation of the malleability of memory. Learning \& Memory, 12, 361-366. doi: 10.1101/1m.94705.

Loftus, E. F., \& Bernstein, D. M. (2005). Rich false memories: the royal road to success. In A. F. Healy (Ed.), Experimental cognitive psychology and its applications (pp. 101-113). Washington DC: American Psychological Association Press.

Loftus, E. F., Donders, K., Hoffman, H. G., \& Schooler, J. W. (1989). Creating new memories that are quickly accessed and confidently held. Memory \& Cognition, 17, 607-616.

Loftus, E. F., Miller, D. G., \& Burns, H. J. (1978). Semantic integration of verbal information into a visual memory. Journal of Experimental Psychology: Human Learning and Memory, 4, 19-31.

Luna, K., \& Martín-Luengo, B. (2012). Confidence-accuracy calibration with general knowledge and eyewitness memory cued recall questions. Applied Cognitive Psychology, 26, 289-295. doi: 10.1002/acp.1822

Mather, M. (2007). Emotional arousal and memory binding: an object-based framework. Perspectives on Psychological Science, 2(1), 33-52. doi: 10.1111/j.17456916.2007.00028.x

McNeely, H. E., Dywan, J., \& Segalowitz, S. J. (2004). ERP indices of emotionality and semantic cohesiveness during recognition judgments. Psychophysiology, 41, 117-129. doi: 10.1111/j.1469-8986.2003.00137.x

Nolan, J., \& Markham, R. (1998). The accuracy-confidence relationship in an eyewitness task: anxiety as a modifier. Applied Cognitive Psychology, 12, 43-54. doi: 10.1002/ (SICI)1099-0720(199802)

Noon, E., \& Hollin, C. R. (1987). Lay knowledge of eyewitness behavior: A British survey. Applied Cognitive Psychology, 1, 143-153. doi: 10.1002/acp.2350010207 
Odinot, G., Wolters, G., \& Giezen, A. (2013). Accuracy, confidence and consistency in repeated recall of events. Psychology, Crime \& Law, 19(7), 629-642, doi: 10.1080/1068316X.2012.660152

Odinot, G., Wolters, G., \& Koppen, P. J. (2009). Eyewitness memory of a supermarket robbery: A case study of accuracy and confidence after 3 months. Law and Human Behavior, 33(6), 506-514. doi: 10.1007/s10979008-9152-x

Paterson, H. M., Kemp, R. I., \& Forgas, J. P. (2009). Cowitnesses, confederates, and conformity: Effects of discussion and delay on eyewitness memory. Psychiatry, Psychology and Law, 16, 112-124.

Paz-Alonso, P. M., \& Goodman, G. S. (2008). Trauma and memory: Effects of post event misinformation, retrieval order, and retention interval. Memory, 16, 58-75. doi: PMID 17852727

Perfect, T. J., Watson, E. L., \& Wagstaff, G. F. (1993). Accuracy of confidence ratings associated with general knowledge and eyewitness memory. Journal of Applied Psychology, 7, 144-147.

Queirós, C. (1997a). Emoções e comportamento desviante, um estudo na perspectiva da personalidade como sistema auto-organizador (Tese de Doutorado). Faculdade de Psicologia e de Ciências da Educação, Universidade do Porto, Portugal.

Queirós, C. (1997b). Toxicodependência e emoções: Um estudo comparativo entre toxicodependentes e não toxicodependentes. Toxicodependências, 3(2), 65-76.

Queirós, C., Asselen, M. van, \& Oliveira, A. (2000). Desencadear emoções através de estímulos olfativos. Saúde Mental, 4, 15-24.

Reisberg, D., \& Heuer, F. (2004). Memory for emotional events. In D. Reiberg, P. Hertel (Eds.), Memory and emotion (pp. 3-41). New York: Oxford University Press.

Rimmele, U., Davachi, L., Petrov, R., Dougal, S., \& Phelps E. A. (2011). Emotion enhances the subjective feeling of remembering, despite lower accuracy for contextual details. Emotion, 11(3), 553-62. doi: 10.1037/a0024246

Rodrigues, E. P., \& Albuquerque, P. B. (2007). Produção de memórias falsas com listas de associados: análise do efeito do nível de processamento e da natureza da prova de memória. Psicologia USP, 18(4), 113-131. doi: 10.1590/S0103-65642007000400008

Santos, R. F., \& Stein, L. M. (2008). A influência das emoções nas falsas memórias: uma revisão crítica. Psicologia USP, 19(3), 415-434. doi: 10.1590/S010365642008000300009

Schaefer, A., Nils, F., Sanchez, X., \& Philippot, P. (2010). Assessing the effectiveness of a large database of emotion-eliciting films: A new tool for emotion researchers. Cognition \& Emotion, 24(7), 1153-1172. doi: 10.1080/02699930903274322

Sharot T., Delgado M. R., \& Phelps E. A. (2004). How emotion enhances the feeling of remembering. Natural Neurosciences, 7, 1376-1380.
Sharot, T. Martorella, E. A., Delgado, M. R., \& Phelps, E. A. (2007). How personal experience modulates the neural circuitry of memories of September 11. PNAS, 104(1), 389-394.

Soleti, E., Curci, A., Bianco, A., \& Lanciano, T. (2012). Does talking about emotions influence eyewitness memory? The role of emotional vs. factual retelling on memory accuracy. Europe's Journal of Psychology, 8(4), 632640. doi: 10.5964/ejop.v8i4.526

Sporer, S. L., Penrod, S., Read, D., \& Cutler, B. (1995). Choosing, confidence, and accuracy: A meta-analysis of the confidence-accuracy relation in eyewitness identification studies. Psychological Bulletin, 11, 315327. doi: 10.1037/0033-2909.118.3.315

Stefanie, F. S., \& Martine B. P. (2012) A comparison of adults witnesses suggestibility across various types of leading questions. Applied Cognitive Psychology, 26, 48-53. doi: 10.1002/acp.1793

Talarico, J., \& Rubin, D. C. (2003). Confidence, not consistency, characterizes flashbulb memories. Psychological Science, 14(5), 455-461. doi: 10.1111/1467-9280.02453

Torres, S., \& Guerra, M. P. (2003). A construção de um instrumento de avaliação das emoções para a anorexia nervosa. Psicologia, Saúde e Doenças, 4(1), 97-110.

Torres, S., Guerra, M. P., Lencastre, L., Roma-Torres, A., Brandão, I., Queirós, C. \& Vieira, F. (2011). Cognitive processing of emotions in anorexia nervosa. Eur Eat Disord Rev., 19(2), 100-114. Doi: 10.10002/erv.1046

Gutiérrez, R. M. V., \& Muñoz-Martínez, A. M. (2013). La regulación emocional: precisiones y avances conceptuales desde la perspectiva conductual. Psicologia USP, 24(2), 225-240. doi: 10.1590/S0103-65642013000200003

Weber, N., \& Brewer, N. (2006). Positive versus negative face recognition decisions: Confidence, accuracy, and response latency. Applied Cognitive Psychology, 20, 1731. doi: 10.1002/acp.1166

Wells, G. L., \& Murray, D. M. (1984). Eyewitness confidence. In G. L. Wells \& E. F. Loftus (Eds.), Eyewitness testimony: Psychological perspectives (pp. 155-170). New York: Cambridge University Press.

Wise, R. A., \& Safer, M. A. (2004). What US judges know and believe about eyewitness testimony. Applied Cognitive Psychology, 18, 427-443. doi: 10.1002/acp.993

Yerkes, R. M., \& Dodson, J. D. (1908). The relation of strength of stimulus to rapidity of habit-formation. Journal of Comparative Neurology and Psychology, 18, 459-148.

Yuille, J. C., \& Cutshall, J. L. (1986). A case study of eyewitness memory of a crime. Journal of Applied Psychology, 71, 291-301. doi: 10.1037/00219010.71.2.291 